\title{
2006-1878: USING SYSTEMS DESIGN TO CONSTRUCT A NEW FRESHMAN COURSE
}

\section{John Robertson, Arizona State University}

John Robertson is a professor in the College of Science and Technology at the ASU Polytechnic in Mesa, Arizona. His research interests are in process control and data management for integrated circuit production, especially novel non-volatile memories. From 1994 to 2001, he was a Director in Motorola's Semiconductor Products Sector and before that, he held the Lothian Chair of Microelectronics at Edinburgh University, UK.

\section{Richard Newman, Arizona State University}

Richard Newman is Director of Training for the Microelectronics Teaching Factory at the ASU Polytechnic campus. He has extensive experience in the community college system and has managed many partnership programs with industry. 


\title{
Using systems design to construct a new freshman course
}

\begin{abstract}
A new first year course must satisfy many requirements in addition to its technical content. In order to meet these expectations, a systems approach was used to set the scope, interfaces and interactions for the first offering in a new four-year degree track. The course is called "An Introduction to Electronic Systems". A life cycle model for the course incorporated the wide range of incoming student capabilities, the outcomes criteria and the role of the course to set expectations for the following program of study. The first delivery in fall 2005 was treated as a prototype within the systems model. While retaining the same scope, the topics will be expanded in 2006-07 to provide a wellrounded $6 \mathrm{SCH}$ first year program. The process used to plan, analyze and record progress is also being applied more generally to overhaul the whole curriculum.
\end{abstract}

\section{Origins}

In the past, the campus operated a $2+2$ system with most students transferring from the local community college system to take upper division university courses to complete their bachelor degrees. The designation of the campus as a Polytechnic in early 2005 introduced many program changes to address the wider educational goals offered by the polytechnic designation. Aggressive recruitment goals have been supported by new freshman and sophomore programs to build a four-year degree track that can operate in parallel with the traditional $2+2$ stream.

Since resources follow student head-count, the new courses had to be introduced in stages and be capable of expansion as they could be justified by enrollment numbers. This is the classic systems design problem where the customer requirements demand a point solution yet everyone knows that it must be capable of evolution to meet goals and operational conditions that are as-yet unspecified. The decision to proceed with a freshman course was made in April 2005 and the course was delivered in the fall semester for the first time. This paper traces the planning, delivery and change process both for the course and its impact on the rest of the Electronics Systems program.

The local engineering-based industry is predominantly associated with three sectors: aerospace, semiconductors and construction. Our department has close ties with all three and their system solution methodologies have been widely used for curriculum planning in industry advisory board meetings, in research collaborations and to deliver industry short courses. There is nothing particularly novel about using systems thinking to examine education programs. A cursory reading of any relevant reports over the past decade from the National Science Foundation ${ }^{1}$ or from the National Academy of Engineering $^{2}$ will show a very refined systems-level view. The problems come at the more mundane and practical levels where the strategy has to be implemented. The usual bottleneck lies in responding to local challenges such as legacy course requirements, limited resources and the need to introduce change seamlessly. In the case for this paper, 
we started with a clean page so it was practically as well as conceptually convenient to take a systems approach to set up the new freshman course. Many excellent examples of new course planning have been presented at ASEE meetings $\left(\mathrm{eg}^{3}\right)$. The justification for presenting another does not lie so much in the novelty of the analysis as in providing a contribution to the body of knowledge on how to do the job. This paper can be seen as a solution within a new set of boundary conditions. By systematically examining the experience of others, the academic community can gradually build up some robust guidelines that will give consistent and reliable results for new course design for modest expenditure of effort.

\section{Systems engineering strategy}

A system is difficult to define as an abstract entity but it is much easier to recognize by its attributes, constraints and management methodology. These features are represented in figure 1 .

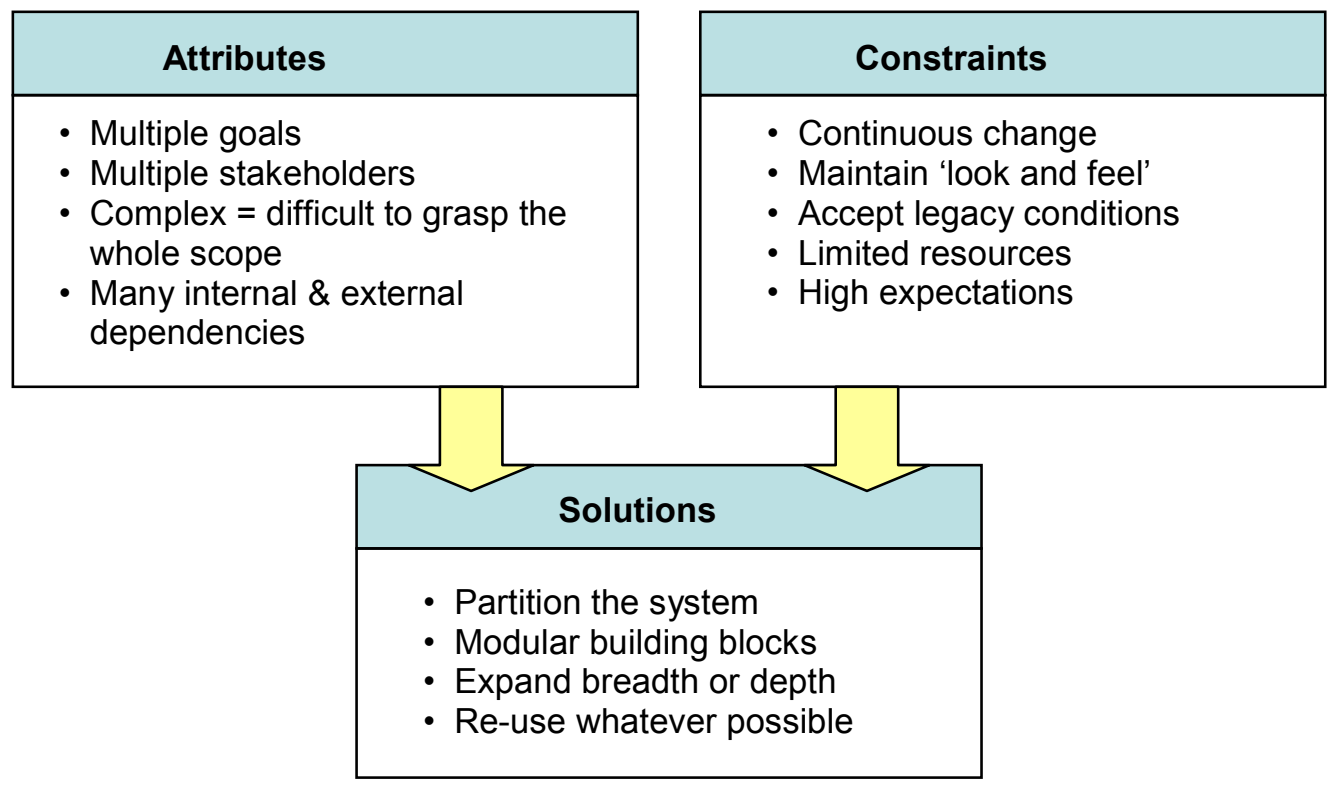

Figure 1. Features of systems

Of all the system features that cause most heartache in practice, the most serious is usually the requirement to evolve smoothly and efficiently while remaining fully operational. As a result, systems engineers throughout the world ${ }^{4}$ have evolved techniques to manage product development ${ }^{5}$. One of the most significant uses a multiphase life-cycle model to provide a compact overview of all the factors that should be considered when the whole system is being specified. Following the practice of our local industry collaborators, we use the 10 stages shown in figure 2: 

1. Analysis of customer needs
2. Define functionality
3. System requirements
4. Major sub-systems
5. Preliminary design
6. Detailed design
7. Product validation
8. Series manufacture
9. Field support operations
10. End of life \& disposal

Figure 2. Stages in the product life cycle

The goal for the first delivery of the new freshman course was to cover the first seven stages and take it to the prototype stage ( \# 7 in figure 2).

\section{Customer needs and course requirements}

The university-level goals and constraints were:

1. Provide a new freshman class to introduce electronic systems.

2. Use it as the lead activity for a restructured lower division program

3. Strengthen links to feeder school districts

4. Maintain compatibility with the existing community college transfer process.

5. Demonstrate the continuous improvement processes we claimed to ABET.

Of these goals, \#3 was the most challenging and even demanded its own systems analysis approach. Although electronics is widely appreciated in high schools, it has a very minor role in the schools' curriculum. The interface dialog has therefore focused on demonstrations to explain the links between the basic sciences and familiar electronics applications. Industry partnerships, summer camps and short courses have all helped the process and of course, they point to the undergraduate program as the next stage.

As the first new course in the new lower division program, it was great to start with a blank page. However, the implications are daunting. Whatever we elected to include would automatically become the platform on which the following courses would have to stand. Fortunately, the top-down viewpoint and work partitioning approach that is inherent to any system design makes that development sequence easier.

\section{Functionality and system goals}

When any new course is mooted, the usual approach is to start with a long list of technical content topics that vie for inclusion. Given the relentless pressure to add more to the technology curriculum, it is inevitable that there should always be many cherished topics looking for a new home. That may be a good tactical argument but it does nothing to address the underlying problem that the curriculum will always be over-full and we should therefore have a process to systematically supplant old material with newer 
treatments. The justification may be obsolescence, shifting faculty interests or simply greater efficiencies in teaching and presentation but change is endemic.

Our solution was to work closely with our industry advisors to develop a balanced scorecard that gives strategy priorities and a systematic process to effect change. Within that context, the process starts with the department's mission, then defines student skills working backwards from graduation and only after that do we populate the framework with the most appropriate technical topics. Such an approach, though common in industry to define products, is not wholeheartedly embraced in academia, so we had our share of lively discussions. The analogy in the academic case presents the student as the product and each course should add value in terms of skills and competencies in a planned and systematic way.

The first step in defining the course functionality was to recognize that first year is a vital buffer between the high school experience and the subsequent university courses with their focus on professional preparation. As a result, the freshman course had to be seen as a recruitment tool. This is particularly important for a subject such as electronics where high school provides experience but little structured explanation of the subject.

Combining the systems approach with local priorities gave a broad set of objectives:

1. Introduce new students to each other and the Department to initiate a positive University educational experience.

2. Contribute to the student roles in the Department's strategy map.

3. Cover all ABET outcomes - by design.

4. Provide a rationale for the future program of study within the Department.

5. Show close coupling between the academic program and industry.

Many of these topics are a form of shorthand. For example, covering the ABET outcomes implies addressing 11 general and 3 subject-specific goals. Likewise, student roles in the department's strategy map cover a whole range of personal, business and technical skills. However, the effect of the systems approach is clear even at this stage. A statement of a technical capability such as being able to design a simple amplifier does not appear until 3 or 4 layers down into the system hierarchy.

\section{Course design and metrics}

Resource and timetable constraints limited the prototype delivery in Fall 2005 to a weekly session worth $2 \mathrm{SCH}$. A systematic development of the objectives led to two divergent requirements. The first was to show the diversity and also the common features of a wide range of electronic systems. The second was to start to build the individual practical skills through group activities. As a result, a list of weekly activities was developed (and more fully described in the next section).

Each weekly activity was mapped on to a series of target scope and performance criteria: 
- The ABET outcomes list.

- Desired skills - personal, business and technical.

- Variety of activities to promote effective learning.

- Links to courses later in the program.

- Match to required incoming skills.

- Address technology development trends (24 items)

- Contributions to the department strategy map and balanced scorecard.

Each of these comparisons was represented using a large spreadsheet. It was not treated as a rigorous checksheet of points and interactions that had to be put in place. However, it was useful as a map to show the diversity within each course activity and to provide a simple profile of the whole course experience. That has been a useful learning activity for everyone and will be applied more generally as a template for other courses.

\section{Prototype delivery}

The course was split into two equal-length modules. The first examined examples of electronics systems in action, specifically:

- A premature baby care unit.

- Facilities control in our semiconductor clean room

- Car testing at General Motors' proving ground

- The State emergency management coordination center.

Web-based preparation and class work was supplemented by visits to the local organizations to see the job being done. In addition, the baby-care unit was the basis of three short team projects to examine data acquisition, maintenance and management of such a unit. The concepts were easily grasped but since no-one had any experience of the activities, the module provided a good starting point to define the subject and develop team-working skills as they analyzed the different interpretations of what they had seen. The limited time available for each topic was fully occupied with preparation, a visit and a short follow-up review. As a result, only the systems features were considered and the students had no problems in working down from the general system requirements to the electronic building blocks. We stopped just at the point where a great deal of additional detailed knowledge would have been required for any further analysis. Hopefully, the class is now more motivated to address these issues in later courses.

The second module was lab-based and we took the opportunity to move away from the traditional "beginners' cook-book" approach. Since the background experience of the class was very diverse (with some ingrained bad habits), the tasks were kept simple. We only considered the measurement of resistance. However, it can take many forms.

The simplest case concentrated on the difference between precision and accuracy and the cost of delivering an additional decimal place. That activity introduced the common lab instruments - and their limitations. The idea that cost increases with the required 
accuracy was accepted readily and demonstrated with the instruments in the teaching lab. However, it was a much harder job to have them accept that a $\pm 1 \%$ voltage and $\pm 1 \%$ current reading could not justify a six-digit value for the derived resistance. The reluctance to round off calculated results is deeply ingrained and perhaps that battle was only fought to a draw.

Temperature changes can lead to drift in values so we next explored stability and error budgets in circuit design. The advantages to be had from using components that were thermally coupled so that resistance values would track with temperature was something of a revelation but readily accepted and used. This was illustrated with simple high gain op-amp circuits. It was then a short step to validating the gain-bandwidth product and the need to be able to understand the content and functionality of data sheets.

The next stage was a big conceptual jump to spreading resistance and the need for calculus to describe diverging fields. Black electrostatic foam provided good samples that could be cut to any desired shape. The sheet resistance was around $20 \mathrm{k} \Omega$ /square but varied enough to lend weight to the earlier lessons on precise measurement. A simple finite difference model was derived using Excel so each student could design, simulate and test their own weird shapes to meet specified resistance values. For all students, this was their first experience that calculus actually had some utility. The capstone lab activity made two resistors from a foam sheet and used them in an op-amp circuit (figure 3 ) to achieve a specified gain. The two cuts shown in figure 3 may seem obvious to make R1 >> R2. However, the class delivered many more creative solutions so there was ample scope to discuss accuracy and the manufacturability of the designs using thin or thick film resistors.

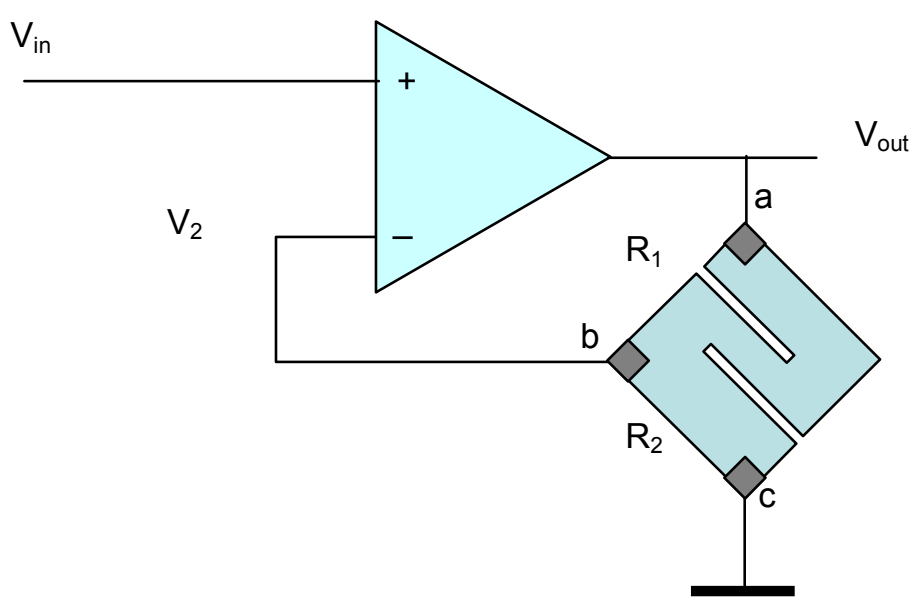

Figure 3. Amplifier with two distributed resistors

The lab activities provide a good framework to emphasize the essential disciplines of preparation, attention to detail, safe working practice and understanding the limits of the tools and procedures. The toughest skill to establish was preparation before starting any lab work. Everyone was used to turning up for a lab class and following a recipe. 
Conceptually, everyone accepted that lab work needed careful planning; they just didn't think it applied to them. All the topics will be examined in greater detail in later courses but the introduction served to demonstrate the rationale behind their overall program of study.

\section{Course Outcomes Assessment}

The scope was about right for the students' learning needs but there was too much to do in the time available. The systems overview was very wide-ranging and the outside visits to examine the diverse applications of the subject worked well. This concept can be developed a lot more. The concentration on resistor properties in the lab sessions also served its purpose well to meet the limited objectives. They did learn a lot about measurement, non-linear effects, numerical solutions of differential equations, the cost of accuracy and the requirements for a robust technology. Learning good lab preparation and measurement discipline has only started and needs consistent reinforcement throughout the program. The goal to justify some of the classes that would follow in later years of the program was recognized and met.

The views of the class were solicited in a questionnaire which is partly reproduced as figure 4 . They were asked to respond numerically using a 4-point scale where 4 indicated strong agreement and 1 strong disagreement with the question or statement.

\begin{tabular}{|c|lc|}
\multicolumn{2}{|l}{} & $\begin{array}{c}\text { Weighted } \\
\text { average }\end{array}$ \\
\hline 1 & The course prepares me for workforce tasks & 3.0 \\
2 & The course is extending by appreciation of the subject & 3.3 \\
3 & We try to cover too much in a class & 1.9 \\
5 & The content matches the published syllabus \& objectives & 3.4 \\
6 & The class slides are detailed enough & 3.3 \\
7 & The content is up to date & 3.6 \\
8 & The course assumes too much I have never seen before & 2.6 \\
9 & This course is harder than my other courses & 2.6 \\
10 & This course absorbs more time than my other courses & 2.6 \\
11 & I would prefer more but simpler assignments & 1.8 \\
12 & The email feedback on preparation before class is helpful & 3.5 \\
13 & I understand the problem after it has been explained & 3.3 \\
14 & I would do better if I spent more time on preparation & 2.6 \\
15 & The preparation helps my understanding in class & 3.1 \\
16 & One week between classes gives enough prep time & 3.3 \\
17 & I would prefer more lecture and less dialog in class & 1.5 \\
18 & The Tablet PC with hand-written additions is effective & 3.4 \\
19 & Writing class comments on slides helps me learn & 3.3 \\
20 & This course is helping me to think more critically & 3.3 \\
21 & The course is improving my work discipline & 2.6 \\
22 & I am getting enough feedback on my performance & 2.8 \\
\hline
\end{tabular}

Scale: 4 = strong YES 1 = strong NO

Figure 4. Summary of student responses 
The range of backgrounds, skills and personalities was wide - more than anticipated. We probably have to accept that's the way it will always be. They picked up technical skills quickly (how to use instruments, spreadsheets, etc). However, they all struggled with work scheduling, explaining ideas they didn't understand well, managing data and applying basic concepts to solve problems. These conclusions came as no surprise, but we have to add to these skills year by year.

The idea of interviewing the hosts during the field trips as a method of learning was new to the class. It emphasized the need to prepare carefully before any activity. They picked up the ideas quickly and the class will be invited back next year. The field trips and the little medical project covered many important issues related to integrity between providers and users.

\section{Program extension}

The concept of mixing a top-down systems view of the subject with a bottom-up lab activity worked well to provide freshmen students with a broad introduction to electronics. The main conclusion was that we should retain roughly the same topics but devote much more time to each. This is in line with the outcome that might be expected from using a systems approach for course planning - the scope is on target but the details turn out to be more extensive than the high-level 'experts' appreciated.

The plan for next year is to expand the $2 \mathrm{SCH}$ prototype to 3 courses spread over both semesters.

1. Introduction to Electronic Systems (3 SCH). It will retain the same scope and goals of the first half of the 2005 prototype class. The project component and industry visits will retain their pivotal place but each will be prefaced with a more structured overview. A follow-up session can then develop the lessons learned from each visit. This arrangement provides more scope for visiting industry speakers as well as coverage of ethics and international perspectives.

2. Use of instruments (1 SCH). Our prototype experience indicated that some students were competent to use the normal range of lab instruments; some thought they were but were not and a few were total novices. Since that variety seems normal in freshmen, we plan to run a self-paced lab course. As well as teaching the use of typical lab instruments, it will cover data collection, typical mistakes, recording and presentation. Each student has set tasks to accomplish and the outcomes are all competency-based.

3. An introductory lab class (2 SCH, spring). With a platform of lab skills established in course \# 2, we can cover the basics of conduction leading to analog and digital functions and provide a platform for new sophomore courses planned for introduction in 2007. 


\section{Conclusions}

The systems approach worked well to cover the broad scope of a new course that had to meet many requirements. Once the process was underway, there were very few serious obstacles. However, the process for review and assessment of the scope statements is complex and needs some familiarity with systems thinking how it is used practically for product development. The prototype delivery met all its objectives and demonstrated how the program could best evolve. The biggest tactical obstacle was the usual problem for newcomers - finding a timetable slot. The tender freshmen only grudgingly embraced the 7.30 am starting time. The biggest deficiency in the prototype delivery was that the students were exposed to many new ideas at a pace that was much faster than they expected. They did respond exceptionally well but the next version of the course will allow much more time for discussion and assimilation.

Starting from a blank page undoubtedly helped to make the systems approach work smoothly. Now we have a template for course planning and evaluation which can be widely applied as other courses are updated and aligned with the top-down systems view for the whole program.

\section{Acknowledgements}

The authors gratefully acknowledge the many constructive inputs from faculty colleagues, Industry Advisory Board members and members of the JACMET Chief Engineer development team. Thanks are also due to the freshman cohort who rose to the challenge with enthusiasm and tolerance. Seed funding was provided as part of NSF grant \# 0230562, “Arizona STEP to Success", National Science Foundation Student Talent Expansion Program Grant

\section{Bibliography}

1. National Science Foundation, "Restructuring engineering education", NSF report 95-65, 1995.

2. National Academy of Engineering, "Educating the engineer of 2020; Adapting engineering education to the new century", NAE, 2005.

3. Lo JL et al., "New paradigm for foundational engineering education", Proc ASEE Conference, Portland, 2005-1262.

4. Details on the International Council on Systems Engineering (INCOSE) can be found at: http://www.incose.org.

5. Barnhill AT \& Gissing B, "Re-evaluating systems engineering concepts using systems thinking", IEEE Trans Systems, Man and Cybernetics, Part C, 28(4), 516-527, 1998. 